\title{
Are we Aware of Preoperative Anxiety?
}

\author{
Ozlem Kocaturk, MD* \\ Department of Oral and Maxillofacial Surgery \& Anesthesiology, Adnan Menderes University, Turkey
}

Submission: February 14, 2019; Published: March 19, 2019

*Corresponding author: Ozlem Kocaturk, Department of Oral and Maxillofacial Surgery, Anaesthesiology and Reanimation, Faculty of Dentistry, Adnan Menderes University, Aydın, Turkey

Keywords: Preoperative anxiety; Anxiety; Nervousness; Fear; Anesthesia; Surgery

\section{Introduction}

The preoperative anxiety is a temporary emotional state caused by anxiety, nervousness, fear and high autonomic nerve system activation arising from these feelings that the patients have prior to the operation [1]. It is known that endocrine systems also play a role in preoperative anxiety symptoms [2]. Preoperative anxiety, a common phenomenon in preoperative patient evaluation, is a process that starts from the date of planning a given operation and progressively intensifies up to the moment of the operation itself. The incidence of preoperative anxiety has been reported to range from $11 \%$ to $80 \%$ among adult patients [3]. In children, preoperative anxiety has been shown to be a risk factor for postoperative state-anxiety [4].

\section{Preoperative Anxiety Overview}

There are many risk factors for preoperative anxiety in patients undergoing elective surgery. History of cancer, psychiatric disorders, future self-perception, depressive symptoms, traitanxiety, pain level, history of smoking, extent of surgery to be performed, female gender, years of formal education and physical status constituted independent risk factors for high preoperative state anxiety [5].

Every patient is known different levels of anxiety due to various aspects such as the previous experiences, personality characteristics, anesthetics and surgery types to be applied and the pain expectation after the surgery [6]. In addition to the negative effects of preoperative anxiety on vital findings, it was also reported that it extends the recovery period and the staying time in hospital and that it has negative effects on postoperative pain and on nausea and vomiting [5,7].

Anxiety can produce aggressive reactions that result in an increase in the distress experienced by the patient, and make the management and control of postoperative pain more difficult $[8,9]$. In addition, anxiety may determine more frequent demands for analgesics in patient-controlled analgesia [10], as well as increased intraoperative anesthetic requirements [3]. It may also produce a lower level of satisfaction with the treatment. Therefore, individuals in charge of preoperative management would probably be more effective in handling a patient's preoperative anxiety if they had more knowledge about potential predictors of preoperative anxiety. Anxiety may interfere substantially with a patient's comfort, quality of life, ability to make appropriate treatment decisions, and treatment compliance, thus affecting survival.

\section{Conclusion}

It is highly important in surgical practice to observe patients carefully and appropriate preoperative anxiety management to avoid the bothersome intraoperative and postoperative results of preoperative anxiety. The measurements of preoperative anxiety should be made as routine procedures. The anxiety levels that will be determined in these routine procedures could facilitate the determination of the premedication doses to be given and prevent to postoperative complications.

\section{References}

1. Markland D, Hardy L (1993) Anxiety, relaxation and anesthesia for day-case surgery. Br J Clin Psychol 32(4): 493-504.

2. Jawaid M, Mushtag A, Mukhtar S, Khan Z (2007) Preoperative anxiety before elective surgery. Neurosciences (Riyadh) 12(2): 145-148.

3. Maranets I, Kain ZN (1999) Preoperative anxiety and intraoperative anesthetic requirements. Anesth Analg 89(6): 1346-1351.

4. Caumo W, Broenstrub JC, Fialho L, Petry SMG, Brathwait O, et al. (2000) Risk factors for postoperative anxiety in children. Acta Anaesthesiol Scand 44(7): 782-789.

5. Caumo W, Schmidt P, Schneider N, Bergmann J, Iwamoto CW, et al (2001) Risk Factors for Preoperative Anxiety in Adults. Acta Anaesthesiol Scand 45(3): 298-307.

6. Kindler CH, Harms C, Amsler F, Ihde-Scholl T, Scheidegger D (2000) The visuel analog skale allows effective measurement of preoperative anxitey and dedection of patient anesthetic concerns. Anesth Analg 90(3): 706-712.

7. SKocaturk O , Oguz E (2017) The effect of preoperative anxiety on the incidence of perioperative bronchospasm: a prospective observational study . Medicine Science 6(4): 746-749. 
8. Anderson EA, Masur FT (1983) Psychological preparation for invasive medical and dental procedures. J Behav Med 6(1): 1-40.

9. Thomas V, Heath M, Rose D, Flory P (1995) Psychological characteristics and the effectivenessof patient-controlled analgesia. Br J Anaesth $74(3): 271-276$

10. Wells JK, Howard GS, Nowlin WF, Vargas MJ (1986) Presurgical anxiety and postsurgical pain and adjustment: effects of a stress inoculation

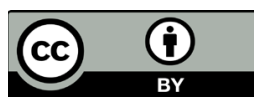

This work is licensed under Creative Commons Attribution 4.0 License

DOI: 10.19080/JAICM.2019.08.555741 procedure. J Consult Clin Psychol 54(6): 831-835.

\section{Your next submission with Juniper Publishers} will reach you the below assets

- Quality Editorial service

- Swift Peer Review

- Reprints availability

- E-prints Service

- Manuscript Podcast for convenient understanding

- Global attainment for your research

- Manuscript accessibility in different formats

( Pdf, E-pub, Full Text, Audio)

- Unceasing customer service

Track the below URL for one-step submission https://juniperpublishers.com/online-submission.php 